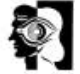

columns

\section{Co-prescribing of atypical and typical antipsychotics: true rate much higher}

Sir: Taylor et al (Psychiatric Bulletin, May 2002, 26, 170-172) rightly point out that co-prescribing may lead to poorer tolerability and increased frequency of anticholinergic effects. Particular attention was not, however, drawn to the possible cardiac side-effects of co-prescribing, especially in the light of recent evidence of antipsychotics causing QT prolongation and subsequent risk of arrhythmias and possible sudden death (Appleby et al, 2000).

I was also struck by the low rate of coprescribing, 53 out of 1441 prescriptions (4\%). In my experience co-prescribing of typicals and atypicals is far more common, especially when 'as-required' medication is taken into account. Not including 'asrequired' medication in the study must result in a significant underestimate of the true rate of co-prescribing

In a recent local audit of antipsychotic prescribing in a group of 160 rehabilitation patients in Norwich, 63 (39\%) were prescribed atypical antipsychotics. Of these 32 (50.8\%) were also prescribed a typical antipsychotic, 15 (23.8\%) regularly and $17(27.0 \%)$ on an as-required basis.

Further research is needed and justification of using a typical and atypical anti psychotic needs to be clear. In a minority of patients, co-prescribing may lead to better symptom control, but, as pointed out, it may be at the expense of increased side-effects.
APPLEBY, L., THOMAS, S., FERRIER, N., et al (2000)

Sudden unexplained death in psychiatric in-patients. British Journal of Psychiatry, 176, 405-406.

Rebecca Horne Specialist Registrar, Julian Hospital, Bowthorpe Road, Norwich NR2 3TD

\section{Nurse uniforms}

Sir: Like Professor Kohen and her colleagues in Lancashire (Psychiatric Bulletin, April 2002, 26, 156), we felt that there may be much to be gained by nursing staff going back to wearing uniforms in our community units for the elderly, where most in-patients have severe dementia. We undertook a study in three units looking at levels of behaviour disturbance before and after the introduction of uniforms in two of the units, with the third unit as a control. The study involved small numbers and is yet to be published, but we too found a decrease in behaviour disturbance in our patient group. This was particularly apparent when patients were receiving assistance with personal care, a time when disturbed behaviour can be a frequent occurrence. The uniforms were universally liked and staff issued with them for the trial all still insist on wearing them, even though the study period ended some time ago.

Unlike our colleagues in Lancashire however, we have not yet been able to reintroduce uniforms across the service, as we would like. We now have to begin the process of persuading the management of the merits of funding uniforms for all the elderly in-patient areas. Any other recent contributions to the evidence base, which would aid our cause, would be most welcome.

Shiela Mackenzie Sector Manager, Jeff Clarke Consultant Psychiatrist, Selby and York Primary CareTrust, Bootham Park Hospital, Bootham, YorkYO30 7BY

\section{Depot injections in the community}

Sir: In his letter on mirror-image studies (Psychiatric Bulletin, April 2002, 26, 155), Professor Hugh Freeman draws attention to the early days of giving depot injections in the community, and says, quite rightly, that this practice coincided with the birth of community psychiatric nursing. Although he mentions the early 1970s as the date of this type of service being given, we, at Herrison Hospital, Dorchester, and St Ann's Hospital, Poole, started nurses giving depot injections in the patients' homes in 1967.

We did not actually know that we were starting a community nursing service, the plan being for ward nurses to have 1 day off the ward a week to give injections to patients that they had nursed in hospital, in the hope that familiarity between nurse and patient would ensure compliance. It was only when an administrator noticed that two nurses had visited two patients in the same street on the same day that it was decreed that a full-time community nurse should be designated.

It might amuse our present-day nursing colleagues that the lady appointed had a case-load of 100 patients.

Alan Gibson Retired Consultant Psychiatrist

\section{the college}

\section{Election results}

\section{President}

The results of the recent election of President are as follows: n of ballot papers distributed n of ballot papers returned n of invalid ballot papers n of valid ballot papers counted

\section{First stage}

Jeremy Holmes

Anton Obholzer

Mike Shooter

\section{Second stage}

Jeremy Holmes

Anton Obholzer

Mike Shooter

(non-transferable

Dr Mike Shooter was therefore elected as President to take office from 27 June 2002

\section{Registrar}

The results of the recent election of Registrar are as follows:

n of ballot papers distributed

9092

n of ballot papers returned

n of invalid ballot papers

$n$ of valid ballot papers counted

2283

4

2279

\section{First stage}

Andrew Fairbairn

Hubert Lacey

Richard Williams

\section{Second stage}

Andrew Fairbairn

Hubert Lacey

Richard Williams

(non-transferable as Registrar to take office from 27 June 2002

\section{Election of Sub-Dean}

Council will be electing a Sub-Dean at its meeting on 24 October 2002. The successful applicant will be the responsible College officer for issues relating to the Specialist Register award of Certificates of Completion of Specialist Training (CCSTs) and take a lead within the College on flexible training. The new Sub-Dean will be expected to be at the College for a minimum of half a day each week, in addition to attending relevant Committees that will include Council (which meets four times a year), the Specialist Training Committee (five times a year) and the Education Committee (three times a year). Any College Member who would like to be considered for this post should write to the Dean, C/o The Royal College of Psychiatrists, Department of Postgraduate Educational Services, 17 Belgrave Square, London SW1X 8PG, for further details. If more than one nomination is received, then an election will be held among Council Members. 